\title{
Reserve Price Formation in Online Auctions
}

\author{
FLORIAN ENGLMAIER \\ ARNO SCHMÖLLER
}

CESIFO WORKING PAPER NO. 2374

CATEGORY 9: INDUSTRIAL ORGANISATION

August 2008
An electronic version of the paper may be downloaded
- from the SSRN website: Www.SSRN.com
- from the RePEc website: Www.RePEc.org
- from the CESifo website: www.CESifo-group.org/wp




\title{
Reserve Price Formation in Online Auctions
}

\begin{abstract}
We use a unique hand collected data set of 6258 auctions from the online football manager game Hattrick to study micro-patterns of reserve price formation. We find that chosen reserve prices exhibit both, very sophisticated and "irrational" behavior by the sellers. Reserve prices pick up the "birthday effect" in sales prices, documented in Englmaier and Schmöller (2008) and are adjusted remarkably nuanced to the resulting sales price pattern. Moreover, reserve prices are too clustered (around multiples of $€ 50000$ ) as to be consistent with fully rational behavior. Furthermore, we find evidence for entitlement effects and the sunk cost fallacy as there is a huge positive effect on the reserve price when the player has been acquired previously.
\end{abstract}

JEL Code: D12, D44.

Keywords: auctions, reserve price, bounded rationality, heuristics, entitlement effect.

\author{
Florian Englmaier \\ University of Munich \\ Ludwigstrasse 28 III VG \\ 80539 Munich \\ Germany \\ englmaier@lmu.de
}

\author{
Arno Schmöller \\ University of Munich \\ Ludwigstrasse 28 III VG \\ 80539 Munich \\ Germany \\ arno.schmoeller@Irz.uni-muenchen.de
}

July 24, 2008

We thank Tobias Böhm, René Cyranek, Matthias Dischinger, Matthias Fahn, and the participants at the Research Workshop "Empirical Economics" in Munich and at the conference "Economics and Psychology of Football 2008” in Innsbruck for their helpful comments and Hans Zenger for inspiration. Moritz Helm provided excellent research assistance. Arno Schmöller gratefully acknowledges the financial support from the German Science Foundation (DFG). 


\section{Introduction}

Auctions have been an important allocation mechanism for a long time. Though not all applications of auctions have been as extraordinary as the legendary auction that occurred in the year 193 A.D. when the entire Roman Empire was auctioned off by the Praetorian Guard to the highest bidder Didius Julianus, they are used in a wide array of fields like art sale, real estate, or spectrum rights. With the ascent of the internet, auctions have exceedingly gained popularity on platforms such as eBay.com, amazon.com, or eBid.com. It is therefore hardly surprising that the field has been studied extensively by many economists. One example is Lucking-Reiley (2000) who presents data from a comprehensive study of 142 different internet auction sites. His results describe the transaction volumes, the types of auction mechanisms used, the types of goods auctioned, and the business models employed at the various sites. From his results it is obvious that an important strategic design element in most auction environments is the reserve or minimum price that can be set by the seller. From the classic contributions in auction theory, Myerson (1981), Riley and Samuelson (1981), or Bulow and Roberts (1989), we have a fairly clear picture about how optimal reserve prices should look - they do not depend on the number of bidders and they are a continuous function of the hazard rate of the distribution of valuations of buyers. ${ }^{1}$ Rosenkranz and Schmitz (2007) extend the analysis to non-standard reference point dependent preferences and show whether and how reserve prices perceived as reference points affect bidding behavior.

However, while there is considerable (although conflicting) empirical evidence on the effect of reserve prices on bidding behavior, there is little empirical evidence on how sellers actually set reserve prices. Using a hand collected data set of 6258 auctions of virtual football players traded in English auctions on hattrick.org we are able to approach this question and provide micro evidence on individual sellers' reserve price choices. ${ }^{2}$ The online game Hattrick (HT) is the world's largest online football manager game with almost one million participants and every day about forty thousand virtual players are traded on the $H T$ transfer market. By design, these trades take place in a highly controlled environment including a standardized duration for each auction, a fixed mode of how players on sale are presented, and no risk of default. Sellers are however free to choose a non-negative reserve price (public minimum bid). Moreover, unlike many other online auction platforms, in HT there is no relation between the minimum bid and the transaction fees a seller is charged, which could bias individuals in their optimal choice of a reserve price. We find both evidence for very sophisticated behavior and boundedly rational behavior in the reserve price patterns in our data.

\footnotetext{
${ }^{1}$ Note however that these predictions are derived in independent private value environments. In interdependent value environments affiliated or common values there are few general results to be found.

${ }^{2}$ Data on auctions of virtual football players traded on hattrick.org have been used previously in studies by Trautmann and Traxler (2008) and by Englmaier and Schmöller (2008).
} 
On the one hand, we find strong evidence that sellers take into account the "birthday effect" as documented in Englmaier and Schmöller (2008). A player's value in the game decreases, ceteris paribus, continuously with his age measured in days as it becomes harder and harder to improve his skills by training. In Englmaier and Schmöller (2008) we show a very strong drop in sales prices just on a player's birthday, indicating that buyers in $H T$ overweigh the age of a player measured in years as opposed to his age measured in days, though the latter is also plainly visible to all buyers free of cost as can be seen in Figure 5 in the appendix. Our analysis of sellers' reserve price formation patterns clearly shows that the birthday effect is also present with respect to reserve prices. Further examination of the data indicates that this is the case not (only) because sellers fall prey to the same information under-usage fallacy as the buyers but because (at least a substantial fraction of) sellers tries to strategically exploit this irrational behavior of the demand side. We find a clustering of sale offers just before players' birthdays, indicating that sellers rationally want to sell players before they drop in value on their birthday. Furthermore, for the same time a spike in the number of unsold players indicates comparably aggressive reserve prices for these players. Finally, a sharp drop of median reserve prices immediately before the birthday indicates that sellers anticipate the immanent drop in market value, trying to make sure the player is sold in time and that a sale is not inhibited by a too aggressive reserve price.

On the other hand, we find that reserve prices are too clustered as to be compatible with fully rational behavior. In particular, the distribution of reserve prices spikes substantially at multiples of $€ 50000$, and also suggests a lower scale clustering at multiples of $€ 5000$. This is in marked contrast to standard auction theoretical results which would predict reserve prices to be a continuous function of the hazard rate of the distribution of buyers' valuations (see eg. Krishna, 2002). We interpret this as evidence for sellers using a round number heuristic in setting reserve prices as the one documented in Benartzi and Thaler (2008) for determining savings choices. The phenomenon of "price clustering" is also well documented for stock markets, where limit sell orders and also prices tend to be rounded to whole numbers rather than displaying fractions. ${ }^{3}$ Also, round integer clustering at multiples of 5 has been suggested earlier (eg. Harris, 1991), resembling the frequent appearance of reserve prices at multiples of $€ 5000$ in our data.

Our regressions provide strong evidence that sellers fall prey to an aggravated entitlement effect, closely related to another prominent bias, the sunk cost fallacy. ${ }^{4}$ In our data we have a very good proxy whether a player on the transfer market had been acquired by the seller previously or whether he was promoted (basically for free) from the seller's own youth team. We find that, ceteris paribus, sellers set substantially and significantly higher

\footnotetext{
${ }^{3}$ Sonnemans (2006) provides an overview on previous studies on price clustering on stock markets and discusses several possible explanations.

${ }^{4}$ Cf. eg. Arkes and Blumer (1985).
} 
reserve prices for players they have bought as compared to players they promoted internally. They are also much more likely (by $9 \%$ ) to set a positive reserve price for those players. Hence it seems that the active purchasing of a player creates an entitlement effect, maybe because sellers do not regard the price they paid as sunk. ${ }^{5}$ There is ample evidence for the entitlement or endowment effect and the resulting Willingness-to-Pay/Willingness-toAccept gap in controlled experiments ${ }^{6}$, though recent work by Plott and Zeiler (2005, 2007) is critical with respect to the validity of the endowment and entitlement effects outside the lab. Our study provides evidence for a strong and persistent entitlement effect in a very competitive natural setting. All our results are robust if we control for the experience of the sellers in our sample. If anything, the entitlement effect seems to be stronger for more experienced sellers. This could be interpreted in line with Huck, Kirchsteiger, and Oechssler (2005) who show theoretically that evolution favors individuals whose preferences embody an endowment effect. The reason is that the endowment effect improves the bargaining position in bilateral trades. Translating this intuition into our setting, experienced sellers are more prone to aggressive rent appropriation for acquired players, securing themselves a larger share of the pie when trade is successful, and allowing them to be more successful in the overall game.

Genesove and Mayer (2001) empirically analyze seller behavior in the Boston residential real estate market using panel data obtained from proprietary records. In their data, sellers whose condominium's expected selling price falls below the original purchase price due to an aggregate market downturn tend to set asking prices well above the expected price level. They argue that this unwillingness to accept market prices for property in the down part of the market cycle could stem from loss aversion on behalf of the sellers. However, in our sample there are no losses caused by business cycle swings, since all data was collected within the period of only a fortnight. The setting studied in Genesove and Mayer (2001) involves bargaining, where the final price can fall below the initial asking price of the seller, which in addition not necessarily reflects his reserve price. It is also reasonable to assume that the evaluation of a condominium may involve substantial search costs, whereas all relevant information on HT's virtual players is readily available, highly standardized, and thus comparable. Hence, while we observe similar behavior of sellers, the motivations behind it may differ considerably.

As alluded to above, though there is to our knowledge very few other evidence on reserve price formation, there are several studies on the effects of reserve prices on selling prices. However, the evidence from those is mixed. While Ariely and Simonson (2003) and Kamins

\footnotetext{
${ }^{5}$ Though this may seem a bit far fetched there is a striking resemblance to the often heard proverb in real world soccer that a "prophet has no honor in his own country," meaning that a player that grew up in a club is oftentimes not as much valued there as other players that have been acquired on the transfer market.

${ }^{6}$ For references see eg. Thaler (1980), Knetsch (1989), Hanemann (1991), Shogren, Shin, Hayes, and Kliebenstein (1994), Casey (1995) or Carmon and Ariely (2000).
} 
et al. (2004) find positive effects of reserve prices on selling prices in field data and in field experiments, Bajari and Hortacsu (2003) and Hoppe and Sadrieh (2007) find no evidence for reference dependence in their field study and field experiment respectively. Of particular interest to us is the study by Trautmann and Traxler (2008), which also uses data from auctions of virtual football players traded in $H T$. The focus of their study is separating two potential channels how reserve prices might affect selling prices: A reference point or anchoring effect as suggested in Rosenkranz and Schmitz (2007) and a standard rent appropriation effect that stems from reserve prices forcing bidders to pay more than the second highest bidders valuation. Trautmann and Traxler (2008) find a positive effect of reserve prices but they find no evidence that any of these higher prices stem from a reference point effect but rather most of this can be accounted for by rent appropriation, as sellers try to set prices competitively between the highest and second highest bidders' valuations.

The remainder of the paper is structured as follows. Section 2 describes the structure of the data and the relevant details of $H T$. Section 3 presents our empirical analysis and its results and Section 4 concludes. All Tables and Figures are collected at the end of the paper.

\section{Data Description}

$H T$ is a browser-based free online football manager game with almost one million registered users, henceforth referred to as "managers". ${ }^{7}$ The basic concept of the game is to manage your own virtual football club, which consists of virtual players that are represented by a multi-dimensional vector of attributes. The tasks for the human managers are manifold, combining the elements of economic management, tactical options, and community interaction. Alongside the sportive component of challenging the teams of other human managers, the game requires the manager to develop a sound financial scheme for his club. The most important source of (virtual in-game) revenue for a manager is successfully trading players on the HT transfer market. Most managers follow a "train and trade" strategy which first ensures the improvement of quality of their own virtual players by choosing a sound training scheme and then profitably trading them with other managers. Since the proceeds from player sales are the major source of income in $H T$, the transfer market provides strong incentives for the participants in this open-ended manager game.

Each player has eight abilities, his "skills", that determine his suitability to play a certain position in the line-up. ${ }^{8}$ From the set of player attributes, only these skills can be actively

\footnotetext{
${ }^{7}$ We refer to human users as "managers", while using the term "player" to address virtual football players.

${ }^{8}$ The eight skills are labeled goalkeeping, stamina, set-pieces, playmaking, winger, scoring, passing, and defense, and the current level is displayed as integer on range 0 to 20 . To all other attributes, we will refer to
} 
improved by the managers via training. However, it takes several weeks for an individual player to increase by a full skill level and only a single skill can be trained at a time. Hence, managers have to specialize in training only one specific skill, say goalkeeping. As soon as such a keeper-trainee surpasses the threshold for a skill-up in this skill, the manager can profitably sell him to another manager and assign the free training slot to a new (and younger) trainee, which he can either acquire on the transfer market or promote directly from his own youth team. ${ }^{9}$ The proceeds from the sales are in turn used to finance the club.

The selling mechanism implemented on the transfer market is an English ascending open bid auction. When selling a player, managers can specify a non-negative reserve price and select a line-up category for the player (e.g. goalkeeper). An auction ends exactly 72 hours from submission, but the deadline is automatically extended by 3 minutes if a bid is placed within 3 minutes to the deadline. This continues until all bidders but one retire. ${ }^{10}$ All players on sale are displayed in the same standardized way and the sellers have no possibility to affect the way how an individual player is presented to potential buyers. A prospective buyer has to submit a bid at least equal to the reserve price or above the current highest bid, respectively. After the auction ends, the player is automatically transferred to the winning manager's team and the seller receives the winning bid net of some small fee. ${ }^{11}$ If a player received no bid, the auction fails and he stays with the seller. Importantly, and in clear contrast to other internet auction platforms, when $H T$ players are on the market, all relevant information concerning their quality - that is the full attribute vector - becomes publicly available. Hence, at the time of sale there is no information asymmetry between buyers and sellers and, for that matter, the econometrician.

The market value of a player to a large extent depends on his current skill levels. In combination with his form and health status, they determine the strength a player adds to a team if he is currently lined-up in a certain position for a match, which we define for the purpose of this paper as his "consumption value" (CV). For instance, a keepers' CV in HT is almost exclusively driven by the goalkeeping-skill. However, the market value is in addition affected through a second channel, which we will call in this paper the "Advancement Potential" (AP) of a player. While the consumption component is independent of a player's age, the AP value strongly depends on the fact that age is a key determinant for training

as "traits" or "characteristics" throughout the paper. A typical player profile with the full set of attributes and the corresponding auction details can be seen in Figure 5 in the Appendix.

${ }^{9}$ Each manager can promote one player from the youth team each week, whose attributes are determined randomly with a high probability of low skills. Age is also randomly assigned on the interval 17 to 19 years.

${ }^{10}$ Given the reserve price is set below the second highest bidder's valuation, the transfer price will equal the second-highest bid plus one discrete increment, i.e. the format is equivalent to a second-price auction. For reference on the effects of the employed ending rule on bidding behavior see eg. Roth and Ockenfels (2002) and Ariely et. al (2005).

${ }^{11}$ The fee is proportional to the transfer price and declines with the time a player is member of the team with a minimum of $2 \%$ after 112 real-time days (an $H T$ year). These transaction costs are small and do not affect any of our results. 
effectiveness. In $H T$, the marginal skill-improvement from training declines with the age of a player. ${ }^{12}$ The younger a player, the more he benefits ceteris paribus from training and the faster he advances to a higher skill level, with which in turn his CV increases. As a consequence, a viable training strategy necessarily requires rather young players, since they have the highest innate potential for further skill development. However, a player who is just a few days younger than another - being otherwise identical - should not be worth much more, since the difference in their AP is minimal. This remains true, even if the one player already turned a year older while the other's birthday lies just ahead. All else equal, a player's AP value decreases continuously with his age measured in days.

Our main interest in this paper is to explain how sellers choose their reserve prices. For this purpose, we focus on a specific subgroup of players: We collected all publicly available information on 6258 virtual players aged between seventeen - the youngest age possible in the game - and nineteen years, all listed as goalkeepers on HT's transfer market. Moreover, all players display the same skill level in goalkeeping (score 6 out of 20), which is the only important skill for a goalie. ${ }^{13}$ By exclusively restricting our sample to this subgroup of players, we create partial homogeneity. As with the goalkeeping-skill the most influential determinant of the $\mathrm{CV}$ is kept constant, we can regard the whole $\mathrm{CV}$ as virtually constant in our data. We are thus able to identify variations of players' APs in the sample, which crucially depend on their age, or more precisely, their total age measured in units of days. The game design is such that all relevant information on the players age attribute is readily available and explicitly stated to every potential bidder.

Next to all relevant player and auction characteristics, we also collected information on buyers and sellers. For a subsample of 2411 auctions we are able to construct a proxy for seller nd buyer experience as we use the information on how a manager ranks relative to all other managers within a given country. We argue that a higher ranking within a country is a good indicator for being more experienced as a higher ranking can only be achieved by playing the game for a long period of time and/or being very successful quickly, which should to a large degree be correlated with having routine playing the game.

Furthermore we use the information whether a player plays abroad or not, indicated by a $20 \%$ bonus on his wage, ${ }^{14}$ as a proxy whether he had been previously traded or whether he is a "fresh" player from the seller's own youth team. Fresh players never receive this $20 \%$

\footnotetext{
${ }^{12}$ Importantly, the marginal effect of training is otherwise homogenous for all virtual players, i.e. there exists nothing like a talent-attribute capturing the potential for skill-improvements. It does, however, to some extent depend on the current skill level (which we hold constant in our sample), the ability of the club's trainer, and the training intensity chosen by the manager, where the latter two give rise to variation in private valuations.

${ }^{13}$ In contrast to goalkeepers, the values of other types of players crucially depend on more than one skill and in addition also on the individual line-up tactics of a manager, making an analysis of the driving forces behind the market value substantially more difficult.

${ }^{14}$ Note that a player's wage is exogenously fixed by $H T$ and cannot be influenced by the managers.
} 
playing-abroad bonus on their wages, as e.g. German teams always produce fresh German players. As in roughly $85 \%$ of all trades buyer and seller are not from the same country, our potential mistake from missing trades within a country is small and this $20 \%$ bonus is a very good proxy to discriminate between fresh and previously traded players.

\section{Analysis and Results}

Our dataset consists of 6258 players with identical goalkeeper-skill that were posted on HT's transfer market between November 18, 2007 and December 02, 2007. ${ }^{15}$ Table 1 shows the summary statistics of the most important variables in our sample. The mean reserve price ( "askprice") in our sample was $€ 77$ 537, but levels as high as $€ 579000$ were reached. Note that the final prices fall in a comparable range, indicating that by and large the reserve prices were not set beside the point. A year in $H T$ is normalized to 112 real-time days and the age of a player is displayed in the form "X years and Y days" on his profile-page. Hence, years defines the age-group of a player, while days discloses information on the distance to the next higher age-level, or equivalently, how far his next birthday is away. For our empirical estimation, we construct the measure totalage $\in[0,335]$, which combines all information contained in both of these two variables and displays the total age of player in day units. ${ }^{16}$

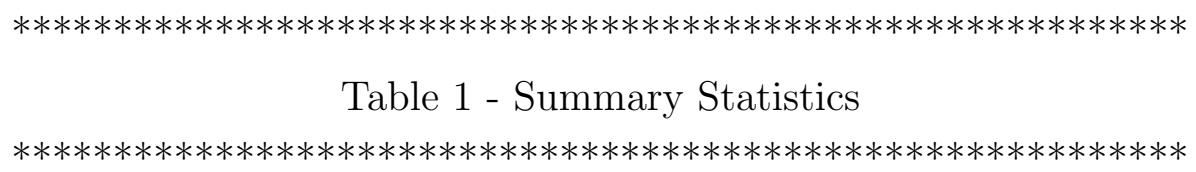

Panel B of Table 1 shows some statistics on the frequency of data. Note that all age-groups are roughly equally represented, with a slight majority of players aged nineteen. According to our wage-bonus proxy (indicated by the dummy dbonus), in about $32 \%$ of all auctions the sellers offered players they previously bought themselves on the market. In $68 \%$ of the times a player promoted from the own youth squad of the seller, i.e. a "fresh" player, was auctioned off. For 5108 players in our sample the sellers fixed a strictly positive reserve price. 4743 of all players were sold, where in 756 cases the trade took place at a price equal to the minimum bid (single bidder case). The fact that a substantial fraction of players remained unsold is evidence that reserve prices were set competitively.

\footnotetext{
${ }^{15}$ We started out with a total sample of 6460 auctions comprising all the auctions of players in the relevant age and skill group in that period. From this we dropped 4 players that play for their respective home country's national team, 66 players with reserve prices identified as outliers by Grubbs' test (Grubbs, 1969) and 132 players that were injured at the time of the auction. This leaves us with 6258 players or $96.9 \%$ of the initial sample.

${ }^{16}$ The variable is calculated as totalage $=112 \cdot($ years -17$)+$ days. Hence, the minimum value of totalage at 0 reflects age "17 years and 0 days" and the maximum value at 335 stands for "19 years and 111 days".
} 
The "Birthday-Effect". In our earlier work on the demand side of HT's transfer market, we find strong evidence for a discontinuous relation between the selling price and age. Hence, it seems a natural point to start our analysis of the driving forces in the formation of reserve prices by similarly examining the relation of reserve price and total age. Intuitively, the variable totalage captures all available information on the players' age attribute, and, as we have argued above, ceteris paribus the value of a player should decline gradually as totalage increases. However, Figure 1 reveals that the relation between reserve price and total age is not smooth but exhibits striking discontinuities where the players enter the next higher age-group. This finding exactly resembles the "birthday effect" we document in Englmaier and Schmöller (2008) for the final selling prices in HT. There, we argue that buyers overweigh the informational content of the age-group indicator years, while they under-use the finer information on a players age attribute given in form of the variable days, leading to suboptimal bidding behavior.

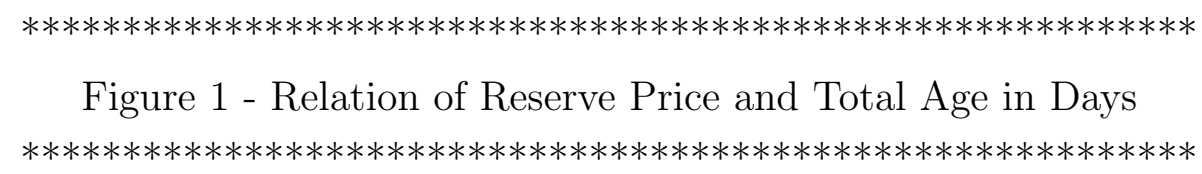

Appropriation of Buyer Surplus. Since most managers in $H T$ alternate between both roles, it seems not too surprising to find similar behavioral patterns for buyers and sellers. At a first glance, it stands to reason that the sellers fall prey to the same suboptimal use of information as the buyers do. However, it is also possible that it is the bias on the demand side that actually triggers the observed choice of reserve prices. That would be the case if at least some sellers follow strategic considerations and try to exploit the biased buyers. To understand whether this is indeed the case, first note that in $15.9 \%$ of the successful trades there was a single bidder only and the winning bid equaled the reserve price (Panel B of Table 1). Building upon the interpretation in Trautmann and Traxler (2008), we take it that in these 756 auctions the sellers successfully managed to appropriate some of the highest bidder's surplus. By setting the reserve price between the latter's and the second highest bidder's valuation, the selling price is mechanically higher than if there was no minimum bid. Furthermore, at least some of the $24 \%$ failed auctions are likely to result from some sellers following this strategy of "rent appropriation" too aggressively and set their reserve price above even the highest bidder's valuation. In line with this argument, a non-parametric Wilcoxon-Mann-Whitney test confirms that the askprices for unsold players are significantly higher than those for successful trades ( $p$-value $=0.000$ ). Though merely inferred by inspection, we take these observations as a first indication that at least some sellers behave strategically and try to reap some of the buyers' surplus. 
An analysis of the age distribution of offered players further strengthens this intuition. Figure 2 depicts the age distribution (measured in day units) for the full sample, sold and unsold players separately. The dashed lines at 112 and 224 mark the points where the players turn eighteen and nineteen, respectively. We find a clustering of sale offers about three weeks before players turn one year older, indicating that sellers rationally want to sell players before they drop in value due to the "birthday effect". Most intriguingly, at about 90 days of total age both the total number of offers and the number of failed auctions increase substantially, while the number of sales (and also the selling price pattern) remains largely constant. ${ }^{17}$ At the same time, in Figure 1 the median askprice exhibits a local peak at exactly the same age level, though this latter finding is not statistically significant. Apparently the sellers are most aggressive in their "rent appropriation" strategy for players that are about to turn one year older and therefore they often exceed the maximum willingness to pay of any potential bidder and fail in their attempt to reap the surplus.

$* * * * * * * * * * * * * * * * * * * * * * * * * * * * * * * * * * * * * * * * * * * * * * * * * * * * * * * * * * * *$

Figure 3 - Reserve Prices in Close Proximity to Discontinuity Point

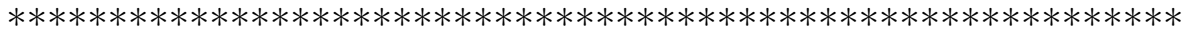

However, in even closer proximity to the day of birthday, a different picture arises, as Figure 3 shows. It depicts all reserve prices two weeks before and after the eighteenth birthday of players (totalage $\in[98 ; 125]$ ). Observe that the median reserve price begins to decline at 110 days of total age and drops to zero at 112, while it moves upwards again immediately after the birthday. Evidentially, many sellers seem to be aware of the value loss that arises through the "birthday effect" and hence try to avoid to bear it themselves. Consequently, they charge low minimum bids for players whose birthday is imminent, thereby minimizing the risk that they remain unsold.

Round number heuristic. Though the above findings point towards rather sophisticated seller behavior, we also find contrasting evidence. For a start, reserve prices are too clustered as to be compatible with fully rational behavior. In particular, Figure 4 clearly shows that the distribution of reserve prices spikes at multiples of $€ 50000$ (Figure 4a), but also at multiples of $€ 5000$ (Figure 4b). This finding stands in marked contrast to standard auction

\footnotetext{
${ }^{17} \mathrm{We}$ find similar, but less pronounced effects at around 200 and 315 days of age, i.e. the 19th and 20th birthday.
} 
theory which would predict reserve prices to be a continuous function of the hazard rate of the distribution of buyers' valuations (see eg. Krishna, 2002). We interpret this as evidence that sellers follow a rule of thumb to considerably simplify their decision making. Our intuition is that they are using a round number heuristic in setting reserve prices as the one documented in Benartzi and Thaler (2008) for determining savings choices. According to Sonnemans (2006), this sort of large scale round number-clustering could be caused by boundedly rational sellers, who form mental target prices, which then serve as a "good enough"-solution in their view instead of demanding the true market value. Note that especially in the light of a rent appropriation strategy as proposed by Trautmann and Traxler (2008) this makes very little sense as this strategy depends on very fine tuned estimates of the distribution of valuations.

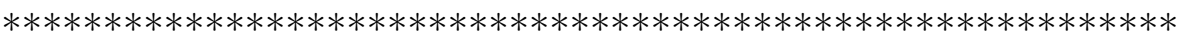

Figure 4 - Patterns and Distribution of Reserve Prices

$* * * * * * * * * * * * * * * * * * * * * * * * * * * * * * * * * * * * * * * * * * * * * * * * * * * * * * * * * *$

Evidence on entitlement effects. Moreover, we find striking evidence that reserve prices strongly differ whether or not a player has been purchased or was instead drafted from a seller's own youth squad. First, among the players that were bought (dbonus=1) the share of failed auctions $(32.6 \%)$ is substantially higher than that for fresh players (20.3\%). Pearson's chi-square test confirms that there is a statistically significant relationship between $d b o n u s$ and the frequency of players remaining unsold ( $\mathrm{p}$-value: 0.000 ). While in principle this could result from a preference for fresh players on behalf of the buyers, ${ }^{18}$ we find strong evidence that sellers chose significantly higher minimum bids for players they acquired on the market. For instance, the mean reserve price for fresh players at $€ 66320$ is substantially below the mean we observe for acquired players at $€ 101331$. This difference is statistically significant on the highest level (non-parametric Mann-Whitney two-sample ranksum, p-value $=0.0000$ ). Apparently, sellers become attached to acquired players and hence demand a premium to give them away again. Stated differently, our findings indicate that sellers in $H T$ exhibit some form of entitlement effect with respect to players they bought on the market, but not for those players they promoted from their own youth squad.

To provide statistical backup for our findings, we employ multi-variate regression analyses with askprice as the dependent variable. Because some of the players with a positive reserve price were not sold, we have a censored sample. We address this by using a Tobit model with left censored reserve price records at value zero in addition to standard OLS with robust

\footnotetext{
${ }^{18}$ In Englmaier and Schmöller (2008) we find such a tendency of the buyers, but the effect is of small magnitude and there is a rational interpretation for a discount on purchased players: A fresh player may be close to the next skill level whereas a previously traded and trained player is more likely to be sold directly after a skill-up. Conversely, for sellers there is no such plausible rationale.
} 
standard errors for all specifications. All results from the OLS regression remain robust without any attenuation. The results from both approaches are shown in Table 2.

$* * * * * * * * * * * * * * * * * * * * * * * * * * * * * * * * * * * * * * * * * * * * * * * * * * * * * * * * * * *$

Table 2 - Multivariate Regression - Determinants of Reserve Price

*******************************************************************

The first and the fourth column of Table 2 contain the coefficients from the simplest specifications we analyzed (OLS I and TOBIT I), using only a subset of the explanatory variables at hand. Remember that the measure totalage by construction represents all available information on the age attribute of a player. Conversely, the age-group dummies agegroup 18 and agegroup 19 only reflect the noisier information contained in the variable years. ${ }^{19}$ Therefore, the latter should all be redundant once we include totalage as explanatory variable. However, the coefficients of agegroup18 and agegroup 19 both are of stunning magnitude and highly significant. By the day players turn eighteen, in model OLS I the expected reserve price slumps down by an average of $€ 88529$ (€92 706 in TOBIT I) with $99 \%$ statistically significant t-statistics. At their nineteenth birthday, players experience another value loss of roughly $€ 11000$, the difference between the coefficients of the age-group dummies, or about $18 \%$ relative to the mean askprice for age-group eighteen (€56 399). A chi-square test approves that both coefficients are jointly significant and also statistically different from each other ( $\mathrm{p}$-value $=0.000$ in OLS I and $\mathrm{p}$-value $=0.012$ in TOBIT I). Hence, both regression models confirm that the "birthday effect" is also present in reserve prices.

We also find indications for sophistication in the seller behavior. In any specification, at least one out of two (correlated) quality indicators has a significant positive relation with askprice. The variables wage and total skill index both are noisy signals of where between the current and the next higher skill-level the player is located, and are correlated at rate $\rho=0.597 .{ }^{20}$ For instance, in model OLS I (TOBIT I) the expected reserve price changes by $€ 20.43$ (€20.11) for each unit increase in total skill index. While the current form is rather volatile and directly affects the player's performance in matches, it is also correlated with the total skill index $(\rho=0.495)$. As we would expect, all three variables are positively related

\footnotetext{
${ }^{19}$ Instead of directly including the variable years we use dummies to indicate the age-group, because our analysis in Englmaier and Schmöller (2008) shows that the effect of a birthday is non-constant across agegroups. Additionally, we include the square of totalage in the estimation model rather than the absolute values to allow for a stronger than linear relationship between the total age (in day units) and the reserve price. All results remain robust if we use a linear specification and/or include years directly.

${ }^{20}$ Since the characteristic wage of the players in our sample is small relative to the observed (reserve) prices, the cost aspect of wage becomes negligible. At the same time, in $H T$ a higher wage ceteris paribus signals that a player is closer to experience a level-up in one of his skills. Hence, the positive sign of the coefficient for wage is plausible.
} 
to the level of the reserve price, even though the influence is sometimes not significant across specifications. ${ }^{21}$

Most intriguingly, the fact whether a player was acquired or promoted internally from the youth squad has a tremendous impact on the choice of the reserve price. As indicated by a large and highly significant coefficient of dbonus, the expected reserve price on average increases by $€ 25815$ in OLS I ( $€ 31449$ in TOBIT I) if a player was previously purchased by the seller. We have similar results in models OLS II and TOBIT II, in which we add the full player attribute vector into the regression, including all skills except goalkeeping, which is identical for all players. We also control for potential auction end day and end time effects adding a dummy for each weekday, and dummies for evening and night hours. ${ }^{22}$ All important influential coefficients from the previous specification remain at the same order of magnitude and are still highly significant. From the skills, only the positive influence of stamina on the reserve price is highly significant. Again, this finding points towards sophisticated seller behavior since stamina is to some extent influential for a goalkeeper's performance.

In the models OLS III and TOBIT III we maintain the full control specification, but only consider experienced sellers $($ sellerxp $<0.2)$ to control for possible learning effects. ${ }^{23}$ We observe that the "birthday effect" is clearly present also among expert sellers as indicated by the large and significant coefficients of the age-group dummies, though the coefficient for agegroup19 is no longer statistically different from that for agegroup18. Furthermore, also the entitlement effect remains robust with experienced sellers. If anything, it seems that the impact of dbonus gets even more pronounced.

Moreover, if a player was previously traded, we find that only in $9.88 \%$ of the cases the reserve price was set to zero. Among fresh players with $20.27 \%$ this share is more than twice as large. As a robustness check, we use logit models to estimate the likelihood for a positive reserve price. ${ }^{24}$ In this specification the dependent variable is $d a s k$, a dummy of value 0 or 1 on whether or not there was a positive minimum bid. The results from these regressions are shown in Table 3.

\footnotetext{
${ }^{21}$ To account for the problem of multicollinearity, we ran diagnostics on the variance inflation factor. The co-movement between the variables turns out to be unproblematic and we keep all three variables in the estimation model. All results remain robust if we drop one or more of them.

${ }^{22}$ We find that for players with a nicer character and more experience a higher askprice is demanded. Moreover, the sellers seem to react to demand fluctuations on the transfer market. For instance, at night hours, where less potential bidders are online simultaneously, we document a significant positive impact on the minimum bid. Since these effects are of secondary order and do not conflict with our main results, the respective coefficients are not displayed in Table 2 to ease the exposition. The full regression tables can be requested from the authors.

${ }^{23}$ The proxy sellerxp takes values on the interval $[0,1]$ and is calculated by dividing the seller's position in the national ranking through the total number of active managers in same country. Using sellerxp $<0.2$ leaves us with a bit less than the $30 \%$ most experienced sellers in the subsample where we can construct the experience dummy.

${ }^{24}$ Using a probit model yields virtually identical results.
} 
$* * * * * * * * * * * * * * * * * * * * * * * * * * * * * * * * * * * * * * * * * * * * * * * * * * * * * * * * * * *$

Table 3 - Logit Regression - Likelihood of Non-Zero Reserve Price

*******************************************************************

The first two columns (Logit I) show the odds ratios (exponentiated coefficients) and the corresponding marginal effects (instantaneous change) in the probability when only the main variables are used as regressors. The regression establishes evidence that a previous acquisition increases the expected likelihood of a non-zero askprice. The dummy agegroup18 and the previous-trade-proxy dbonus are statistically significant on the highest level. In other words, the likelihood for a strictly positive reserve price decreases if a player turns eighteen. Conversely, the effect of dbonus on the likelihood for a non-zero reserve price is large and positive: For a purchased player $(d b o n u s=1)$ the odds of a strictly positive reserve price (versus a zero reserve price) increases by a factor of 2.3 as compared to a player that was promoted from a manager's own youth team. In terms of the marginal effect, a non-zero reserve price is 11 percent more likely for previously acquired players. ${ }^{25}$ If we again employ the full vector of player and auction attributes as controls (Logit II), all results remain qualitatively robust. In line with our previous results, a separate regression for expert sellers (Logit III) reveals that, if anything, the effect is more pronounced for experts.

Hence, if a player was bought rather than promoted, on average not only the absolute level of the reserve price is higher, but also the likelihood that it is set different from zero at all. Both findings suggest that the sellers are prone to an aggravated entitlement effect for players that they purchased on the market beforehand, but not if a player was promoted from their own youth team. Since the managers in HT engage in a highly competitive environment this result is even more startling, since it is an common argument that such entitlement effects vanish if competition gets more intense (see e.g. Plott and Zeiler, 2007) or of goods are purchased for resale (see e.g. Kahnemann, 2003).

\section{Conclusion}

We examine empirically how managers playing the online game $H T$ set reserve prices in auctions for virtual players. Using detailed field data on 6258 auctions from HT's transfer market, we find that chosen reserve prices exhibit both, very sophisticated and "irrational" behavior by the sellers. Reserve Prices pick up the "birthday effect" in sales prices, documented in Englmaier and Schmöller (2008) and are adjusted remarkably nuanced to the resulting sales price pattern.

\footnotetext{
${ }^{25}$ The marginal change is the partial derivative of the predicted probability w.r.t. an independent variable.
} 
Evidentially, while many sellers act strategically and try to reap some of the buyers' surplus, some fail in this endeavor as they set reserve prices too aggressively. In addition, we have established that reserve prices are too clustered (around $€ 50000$ steps) as to be consistent with fully rational behavior. Most intriguingly, even though $H T^{\text {'s }}$ s transfer market is highly competitive, we find strong evidence for an entitlement effect in form of a huge positive effect on the reserve price when a player has been acquired previously. All our results are robust when we control for the experience of sellers, and the auction-end-day and time-of-day effects. Hence we conclude that $H T$ managers simplify their decision making by adopting heuristic pricing rules that are suboptimal from a fully rational point of view. In particular, the strong entitlement effect we document most plausibly is a ramification of psychological motivations like the sunk cost fallacy or loss aversion. Abstracting from skillimprovements for the moment, for any purchased player a seller may always use the paid price as a direct benchmark. Though this cost is sunk by then, sellers might be tempted to charge at least the same amount, or even an additional mark-up, as reserve price. Since however their valuation was the highest in the previous auction, this might be too high a threshold. For promoted players, in contrast, there is no such benchmark to anchor upon. If, as in our data, this entitlement effect is persistent and quantitatively relevant, the option of choosing a reserve price might be an impediment to market efficiency as sellers set too high reserve prices resulting in too little trade. In such situations the social planner might want to avoid using a reserve price in the design of an auction format to avoid this potential distortion. On the upside, our paper suggests that simple microeconomic theory gives us a lot of mileage in explaining market behavior in complex environments. We document that (the majority of) sellers very finely adjust their behavior to demand patterns and try to strategically exploit potential arbitrage possibilities.

Games like $H T$, where people strategically interact, not only attract increasing numbers of customers, but also create new markets and business ideas. We are convinced that the vast amount of data generated by social gaming involving thousands of motivated online gamers provides a fruitful source for valuable insights and can contribute to the analysis of human decision making.

\section{References}

1. Ariely, D., A. Ockenfels, and A.E. Roth (2005) "An experimental analysis of ending rules in Internet auctions," RAND Journal of Economics, Vol. 36(4), pp. 891-908

2. Ariely, D. and I. Simonson (2003) "Buying, Bidding, Playing, or Competing? Value Assessment and Decision Dynamics in Online Auctions," Journal of Consumer Psychology, Vol. 13(1\&2), pp. 113-123 
3. Arkes, H. and C. Blumer (1985) "The Psychology of Sunk Cost," Organizational Behavior and Human Decision Process, Vol. 35, pp. 124-140

4. Bajari, P. and A. Hortacsu (2003) "Winner's Curse, Reserve Prices and Endogenous Entry: Empirical Insights from eBay," RAND Journal of Economics, Vol. 34, pp. 329-355

5. Benartzi, S. and R.H. Thaler (2008) "Heuristics and Biases in Retirement Savings Behavior," Journal of Economic Perspectives, forthcoming

6. Bulow, J. and J. Roberts (1989) "The Simple Economics of Optimal Auctions," The Journal of Political Economy, Vol. 97(5), pp. 1060-1090

7. Carmon, Z. and D. Ariely (2000) "Focusing on the Forgone: How Value Can Appear so Different to Buyers and Sellers," The Journal of Consumer Research, Vol. 27(3), pp. $360-370$

8. Casey, J.T. (1995) "Predicting Buyer-Seller Pricing Disparities," Management Science, Vol. 41(6), pp. 979-999

9. Englmaier, F. and A. Schmöller (2008) "Bidding Behavior in Online Auctions - Micro Evidence from the Online Game Hattrick," mimeo

10. Genesove, D. and C. Mayer (2001) "Loss Aversion And Seller Behavior: Evidence From The Housing Market," The Quarterly Journal of Economics, Vol. 116(4), pp. $1233-1260$

11. Grubbs, F. (1969) "Procedures for Detecting Outlying Observations in Samples", Technometrics, 11(1), pp. 1-21.

12. Hanemann, W.M. (1991) "Willingness to Pay and Willingness to Accept: How Much Can They Differ?," The American Economic Review, Vol. 81(3), pp. 635-647

13. Harris, L. (1991) "Stock price clustering and discreteness", Review of Financial Studies, Vol. 4, pp. 389-415

14. Hoppe, T. and A. Sadrieh (2007) "An Experimental Assessment of Confederate Reserve Price Bids in Online Auctions," mimeo

15. Huck, S., G. Kirchsteiger, and J. Oechssler (2005) "Learning to like what you have explaining the endowment effect," Economic Journal, Vol. 115(505), pp. 689-702

16. Kahneman, D. (2003) "Maps of bounded rationality: Psychology for behavioral economics," The American Economic Review, Vol. 93, 1449-1475 
17. Kamins, M.A., X. Dreze, and V.S. Folkes (2004) "Effects of Seller-Supplied Prices on Buyers' Product Evaluations: Reference Prices in an Internet Auction Context," Journal of Consumer Research, Vol. 30, pp. 622-628

18. Knetsch, J.L. (1989) "The Endowment Effect and Evidence of Nonreversible Indifference Curves," The American Economic Review, Vol. 79(5), pp. 1277-1284

19. Krishna, V. (2002) "Auction Theory," Academic Press

20. Lucking-Reiley, D. (2000) "Auctions on the Internet: What's Being Auctioned, and How?," The Journal of Industrial Economics, Vol. 48(3), pp. 227-252

21. Myerson, R.B. (1981) "Optimal auction design," Mathematics of Operations Research, Vol. 6, pp. 58-73

22. Ockenfels, A. and A.E. Roth (2002) "Last-Minute Bidding and the Rules for Ending Second-Price Auctions: Evidence from eBay and Amazon Auctions on the Internet," The American Economic Review, Vol. 92(4), pp. 1093-1103

23. Plott, C.R. and K. Zeiler (2005) "The Willingness to Pay/Willingness to Accept Gap, the Endowment Effect, Subject Misconceptions and Experimental Procedures for Eliciting Valuations," The American Economic Review, Vol. 95(3), pp. 530-545

24. Plott, C.R. and K. Zeiler (2007) "Exchange Asymmetries Incorrectly Interpreted as Evidence of Endowment Effect Theory and Prospect Theory?," The American Economic Review, Vol. 97, p. 1449

25. Riley, J.G. and W.F. Samuelson (1981) "Optimal Auctions," The American Economic Review, Vol. 71(3), pp. 381-392

26. Rosenkranz, S. and P.W. Schmitz (2007) "Reserve prices in auctions as reference points," Economic Journal 117, 637-653

27. Shogren, J.F., S.Y. Shin, D.J. Hayes, and J.B. Kliebenstein (1994) "Resolving Differences in Willingness to Pay and Willingness to Accept," The American Economic Review, Vol. 84(1), pp. 255-270

28. Sonnemans, J. (2006) "Price clustering and natural resistance points in the Dutch stock market: a natural experiment," European Economic Review, Vol. 50, pp. 1937-1950

29. Thaler, R. (1980) "Towards a positive theory of consumer choice," Journal of Economic Behavior and Organization, Vol. 1, pp. 39-60

30. Trautmann, S.T. and C. Traxler (2008) "Reserve prices as reference points - Evidence from auctions for football players at hattrick.org," mimeo 


\section{$6 \quad$ Tables and Figures}

Table 1: Summary Statistics

\begin{tabular}{|c|c|c|c|c|c|c|c|}
\hline \multicolumn{4}{|c|}{ Panel A. } & \multicolumn{4}{|c|}{ Panel B. } \\
\hline Variable & Mean & Min & Max & & Variable Value & Frequency & Percent \\
\hline askprice & 77537 & 0 & 579000 & age distribution & $($ years $=17)$ & 1886 & 30.14 \\
\hline price $^{a}$ & 81459 & 0 & 634000 & & $($ years $=18)$ & 1935 & 30.92 \\
\hline years & 18 & 17 & 19 & & $($ years $=19)$ & 2437 & 38.94 \\
\hline days & 59 & 0 & 111 & & & & \\
\hline totalage $^{b}$ & 181 & 3 & 335 & fresh players & $($ dbonus $=0)$ & 4253 & 67.96 \\
\hline total skill index & 1994 & 650 & 3240 & purchased players & $($ dbonus $=1)$ & 2005 & 32.04 \\
\hline wage & 1884 & 770 & 2676 & & & & \\
\hline form & 6 & 1 & 8 & reserve price & (askprice >0) & 5108 & 81.62 \\
\hline stamina & 3 & 1 & 9 & no reserve price & (askprice $=0)$ & 1150 & 18.38 \\
\hline passing & 1 & 1 & 4 & & & & \\
\hline playmaking & 1 & 1 & 3 & successful trades & $($ price $>0)$ & 4743 & 75.79 \\
\hline scoring & 1 & 1 & 3 & players unsold & $($ price $=0)$ & 1515 & 24.21 \\
\hline winger & 1 & 1 & 4 & & & & \\
\hline setpieces & 2 & 1 & 7 & sold at reserve pric & (price $=$ askprice $)$ & 756 & 15.94 \\
\hline defense & 1 & 1 & 4 & & & & (of all sold) \\
\hline
\end{tabular}

a. A Price of zero indicates a failed auction. The minimum price among all successful trades was $€ 19000$.

b. The measure for total age is calculated as totalage $=112 \cdot($ years-17 $)+$ days. It displays a players age in day units and is normalized such that the minimum value of totalage at 0 reflects age " 17 years and 0 days" and the maximum value at 335 stands for "19 years and 111 days".

Table 2: Multivariate Regression - Determinants of Reserve Price

\begin{tabular}{|c|c|c|c|c|c|c|}
\hline & $\begin{array}{c}\text { OLS I } \\
\text { no controls }\end{array}$ & OLS II & $\begin{array}{c}\text { OLS III } \\
\text { expert sellers }\end{array}$ & $\begin{array}{c}\text { Tobit I } \\
\text { no controls }\end{array}$ & Tobit II & $\begin{array}{c}\text { Tobit III } \\
\text { expert sellers }\end{array}$ \\
\hline agegroup18 & $\begin{array}{l}-88529.73^{* * *} \\
(2720.41)\end{array}$ & $\begin{array}{l}-88663.06^{* * *} \\
(2730.02)\end{array}$ & $\begin{array}{l}-87625.39^{* * *} \\
(7835.08)\end{array}$ & $\begin{array}{l}-92706.27^{* * *} \\
(3099.74)\end{array}$ & $\begin{array}{l}-92923.12^{* * *} \\
(3095.09)\end{array}$ & $\begin{array}{l}-95038.57^{* * *} \\
(9367.06)\end{array}$ \\
\hline agegroup19 & $\begin{array}{c}-99150.27 \text { *** } \\
(3992.42)\end{array}$ & $\begin{array}{l}-97663.81^{* * * *} \\
(4032.39)\end{array}$ & $\begin{array}{l}-89941.40^{* * *} \\
(12021.47)\end{array}$ & $\begin{array}{c}-103822.60^{* * *} \\
(6100.97)\end{array}$ & $\begin{array}{c}-101995.20^{* * *} \\
(6072.99)\end{array}$ & $\begin{array}{l}-97106.86^{* * *} \\
(19234.19)\end{array}$ \\
\hline totalage $^{2}$ & $\begin{array}{l}-0.13^{* * *} \\
(0.04)\end{array}$ & $\begin{array}{l}-0.14^{* * *} \\
(0.04)\end{array}$ & $\begin{array}{l}-0.27^{* *} \\
(0.13)\end{array}$ & $\begin{array}{l}-0.16^{* *} \\
(0.07)\end{array}$ & $\begin{array}{l}-0.18^{* *} \\
(0.07)\end{array}$ & $\begin{array}{l}-0.34 \\
(0.24)\end{array}$ \\
\hline total skill index & $\begin{array}{l}20.43^{* * *} \\
(4.92)\end{array}$ & $\begin{array}{l}20.17^{* * *} \\
(4.82)\end{array}$ & $\begin{array}{r}18.71 \\
(17.21)\end{array}$ & $\begin{array}{l}20.11^{* * *} \\
(4.45)\end{array}$ & $\begin{array}{l}19.57^{* * * *} \\
(4.42)\end{array}$ & $\begin{array}{c}28.06^{*} \\
(16.26)\end{array}$ \\
\hline wage & $\begin{array}{l}17.45^{* *} \\
(7.88)\end{array}$ & $\begin{array}{l}18.49^{* *} \\
(7.74)\end{array}$ & $\begin{array}{r}22.94 \\
(30.74)\end{array}$ & $\begin{array}{l}19.65^{* * *} \\
(7.01)\end{array}$ & $\begin{array}{l}21.72^{* * *} \\
(7.02)\end{array}$ & $\begin{array}{r}21.47 \\
(28.97)\end{array}$ \\
\hline form & $\begin{array}{l}-2767.89^{* *} \\
(1203.09)\end{array}$ & $\begin{array}{l}-1276.34 \\
(1247.10)\end{array}$ & $\begin{array}{l}-1564.55 \\
(3643.78)\end{array}$ & $\begin{array}{l}-3165.42^{* * *} \\
(1218.45)\end{array}$ & $\begin{array}{l}-1175.64 \\
(1253.45)\end{array}$ & $\begin{array}{l}-1060.93 \\
(3848.84)\end{array}$ \\
\hline $\begin{array}{l}\text { acquired } \\
(\text { dbonus }=1)\end{array}$ & $\begin{array}{l}25815.38^{* * *} \\
(2964.97)\end{array}$ & $\begin{array}{l}21127.71^{* * *} \\
(3076.64)\end{array}$ & $\begin{array}{l}39040.31^{* * * *} \\
(11143.74)\end{array}$ & $\begin{array}{l}31448.75^{* * * *} \\
(2834.87)\end{array}$ & $\begin{array}{l}25114.21 * * * \\
(2958.61)\end{array}$ & $\begin{array}{l}50265.09^{* * *} \\
(12155.47)\end{array}$ \\
\hline skills & no & yes & yes & no & yes & yes \\
\hline daytime & no & yes & yes & no & yes & yes \\
\hline weekday & no & yes & yes & no & yes & yes \\
\hline character & no & yes & yes & no & yes & yes \\
\hline$R^{2}$ & 0.38 & 0.39 & 0.46 & & & \\
\hline $\mathrm{N}$ & 6258 & 6258 & 748 & $\begin{array}{c}6258 \\
\text { (1150 left-cens.) } \\
\end{array}$ & $\begin{array}{c}6258 \\
\text { (1150 left-cens.) } \\
\end{array}$ & $\begin{array}{c}748 \\
\text { (181 left-cens.) } \\
\end{array}$ \\
\hline
\end{tabular}

Notes: Standard errors are stated in parentheses (robust for OLS). Asterisks denote statistical significance at the $1 \%(* * *)$, $5 \%(* *)$ or $10 \%\left(^{*}\right)$ level. Sellers are classified as experts if sellerxp $<0.2$. "Skills" captures the playing abilities except of "goalkeeping" (= constant at score 6). "Character" contains all other player attributes. "Daytime" and "weekday" indicate whether dummies for daytime and day of the week were included. 
Table 3: Logit Regression - Likelihood of Non-Zero Reserve Price

\begin{tabular}{|c|c|c|c|c|c|c|}
\hline & \multicolumn{2}{|c|}{$\begin{array}{c}\text { Logit I } \\
\text { no controls }\end{array}$} & \multicolumn{2}{|c|}{ Logit II } & \multicolumn{2}{|c|}{$\begin{array}{c}\text { Logit III } \\
\text { expert sellers }\end{array}$} \\
\hline & Odds Rt. & Marg.Efct. & Odds Rt. & Marg.Efct. & Odds Rt. & Marg.Efct. \\
\hline agegroup18 & $\begin{array}{l}0.675^{* * *} \\
(0.074)\end{array}$ & -0.0559 & $\begin{array}{l}0.681^{* * *} \\
(0.076)\end{array}$ & -0.053 & $\begin{array}{l}0.539 * * \\
(0.160)\end{array}$ & -0.1001 \\
\hline agegroup19 & $\begin{array}{c}0.708^{*} \\
(0.143)\end{array}$ & -0.049 & $\begin{array}{r}0.760 \\
(0.156)\end{array}$ & -0.038 & $\begin{array}{r}0.632 \\
(0.358)\end{array}$ & -0.0743 \\
\hline totalage 2 & $\begin{array}{r}1.000 \\
(0.000)\end{array}$ & 0 & $\begin{array}{r}1.000 \\
(0.000)\end{array}$ & 0.000 & $\begin{array}{r}1.000 \\
(0.000)\end{array}$ & 0 \\
\hline total skill index & $\begin{array}{r}1.000 \\
(0.000)\end{array}$ & 0 & $\begin{array}{r}1.000 \\
(0.000)\end{array}$ & 0.000 & $\begin{array}{r}1.001 \\
(0.001)\end{array}$ & 0.0001 \\
\hline wage & $\begin{array}{r}1.000 \\
(0.000)\end{array}$ & 0 & $\begin{array}{r}1.000 \\
(0.000)\end{array}$ & 0.000 & $\begin{array}{r}1.000 \\
(0.001)\end{array}$ & 0 \\
\hline form & $\begin{array}{r}0.966 \\
(0.043)\end{array}$ & -0.0049 & $\begin{array}{r}1.037 \\
(0.049)\end{array}$ & 0.005 & $\begin{array}{r}1.131 \\
(0.144)\end{array}$ & 0.0199 \\
\hline $\begin{array}{l}\text { acquired } \\
(\text { dbonus }=1)\end{array}$ & $\begin{array}{l}2.322^{* * *} \\
(0.266)\end{array}$ & 0.1197 & $\begin{array}{l}1.882^{* * *} \\
(0.230)\end{array}$ & 0.088 & $\begin{array}{l}5.057^{* * *} \\
(2.422)\end{array}$ & 0.2622 \\
\hline skills & no & & yes & & yes & \\
\hline daytime & no & & yes & & yes & \\
\hline weekday & no & & yes & & yes & \\
\hline character & no & & yes & & yes & \\
\hline $\mathrm{N}$ & 6258 & & 6258 & & 748 & \\
\hline
\end{tabular}

Notes: For each specification the respective odds ratio and marginal effect for the regressors used to predict dask are shown. Standard errors are stated in parentheses (robust for OLS). Asterisks denote statistical significance at the $1 \%(* * *), 5 \%(* *)$ or $10 \%(*)$ level. Sellers are classified as experts if sellerxp $<0.2$. Groups of controls identical to those in Table 2 .

Table 4: List of Variables

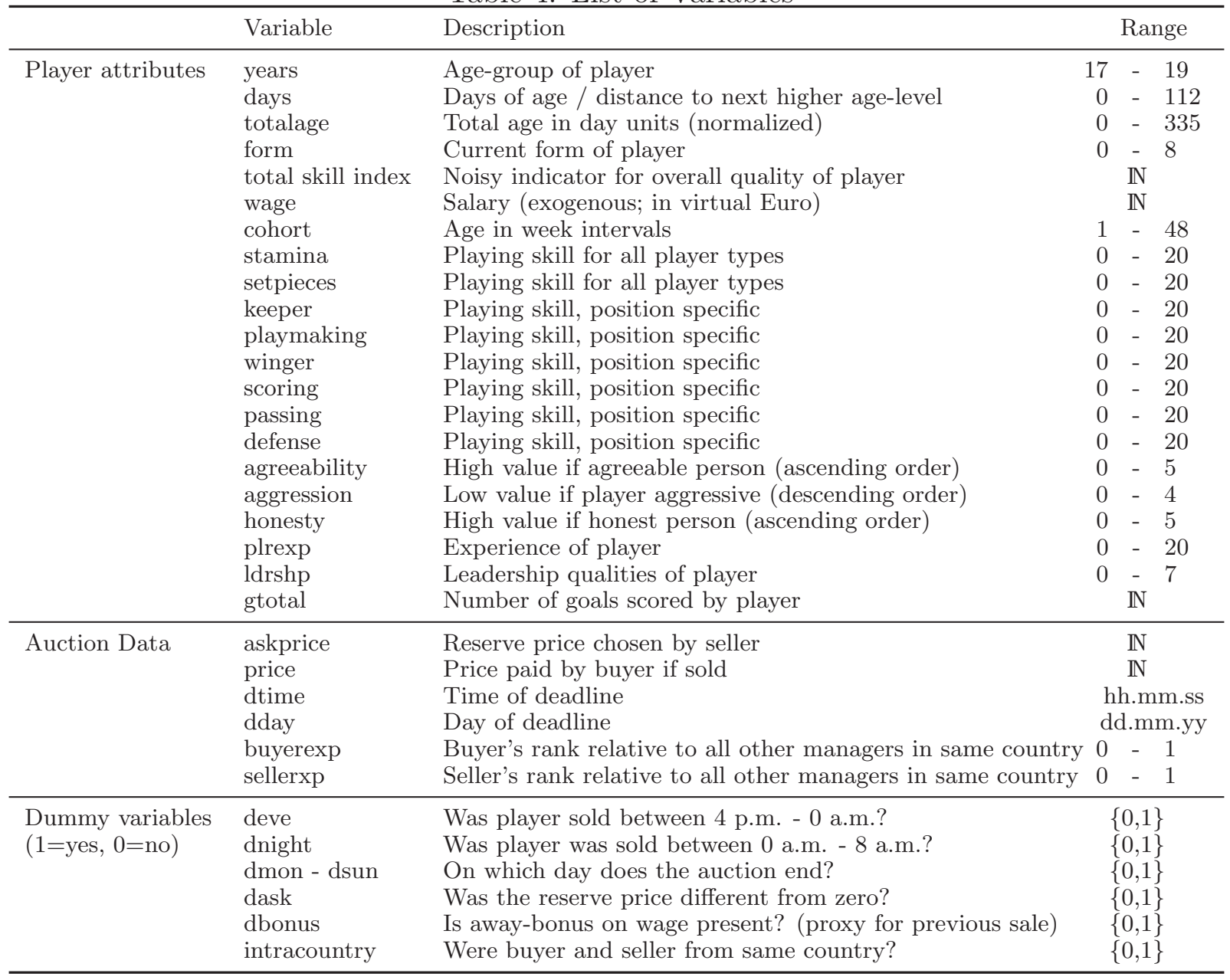


Figure 1: Relation of Reserve Price and Total Age in Days

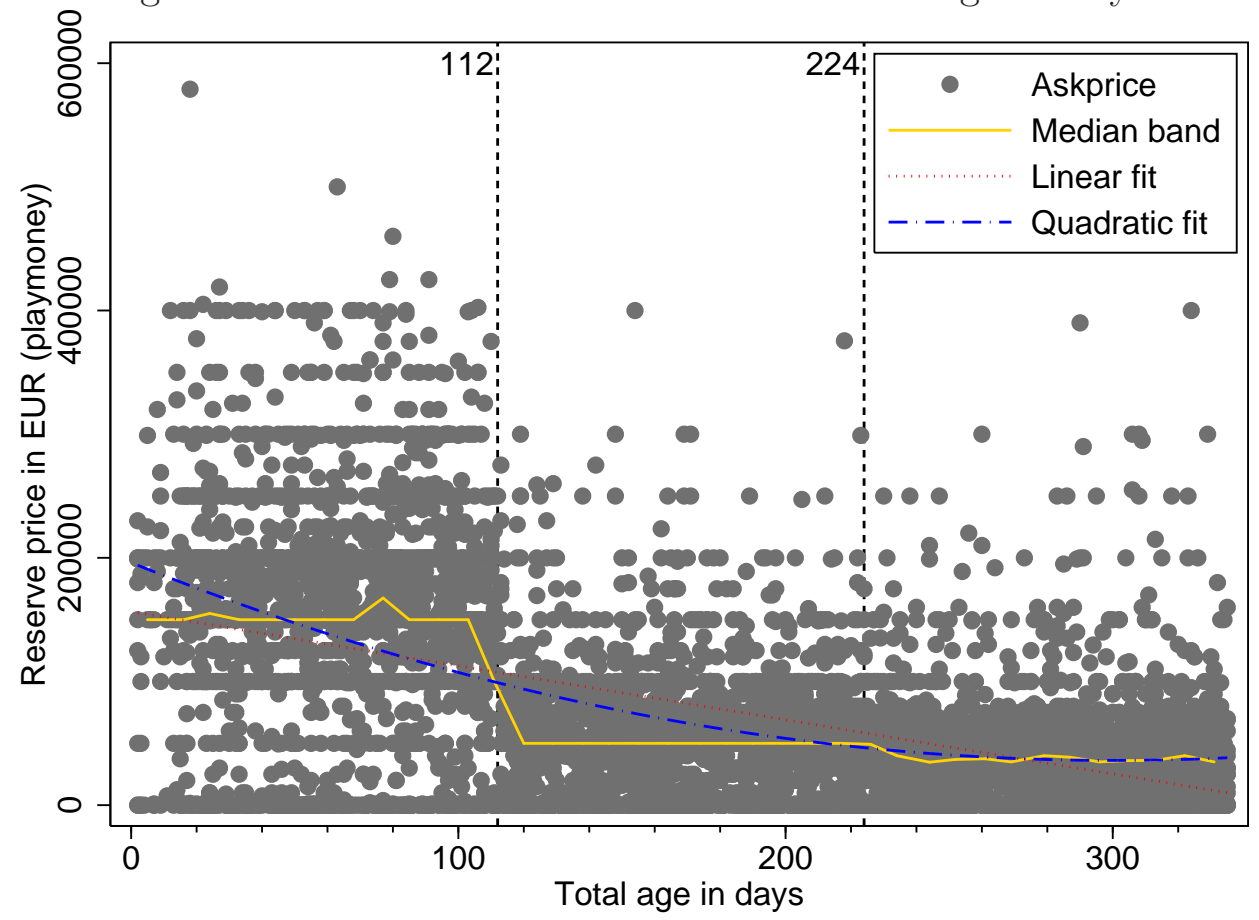

Notes: The measure for total age in days is calculated as totalage $=112 \cdot($ years -17$)+$ days. It is normalized such that the minimum value of totalage at 0 reflects age "17 years and 0 days" and the maximum value at 335 stands for "19 years and 111 days".

Figure 2: Age Distribution of Sold and Unsold Players

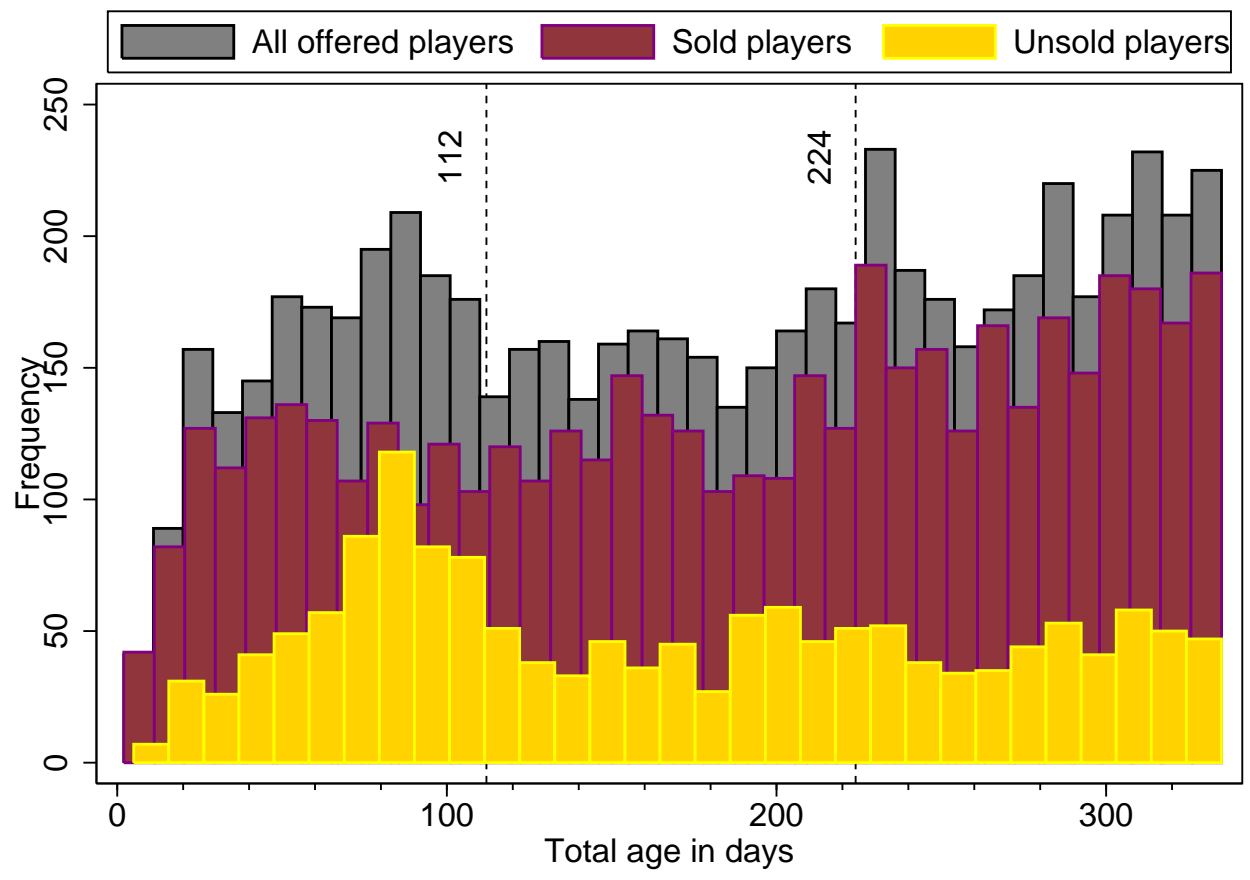

Notes: The measure for total age in days is calculated as totalage $=112 \cdot($ years- 17$)+$ days. It is normalized such that the minimum value of totalage at 0 reflects age "17 years and 0 days" and the maximum value at 335 stands for "19 years and 111 days". 
Figure 3: Reserve Prices in Close Proximity to Discontinuity Point

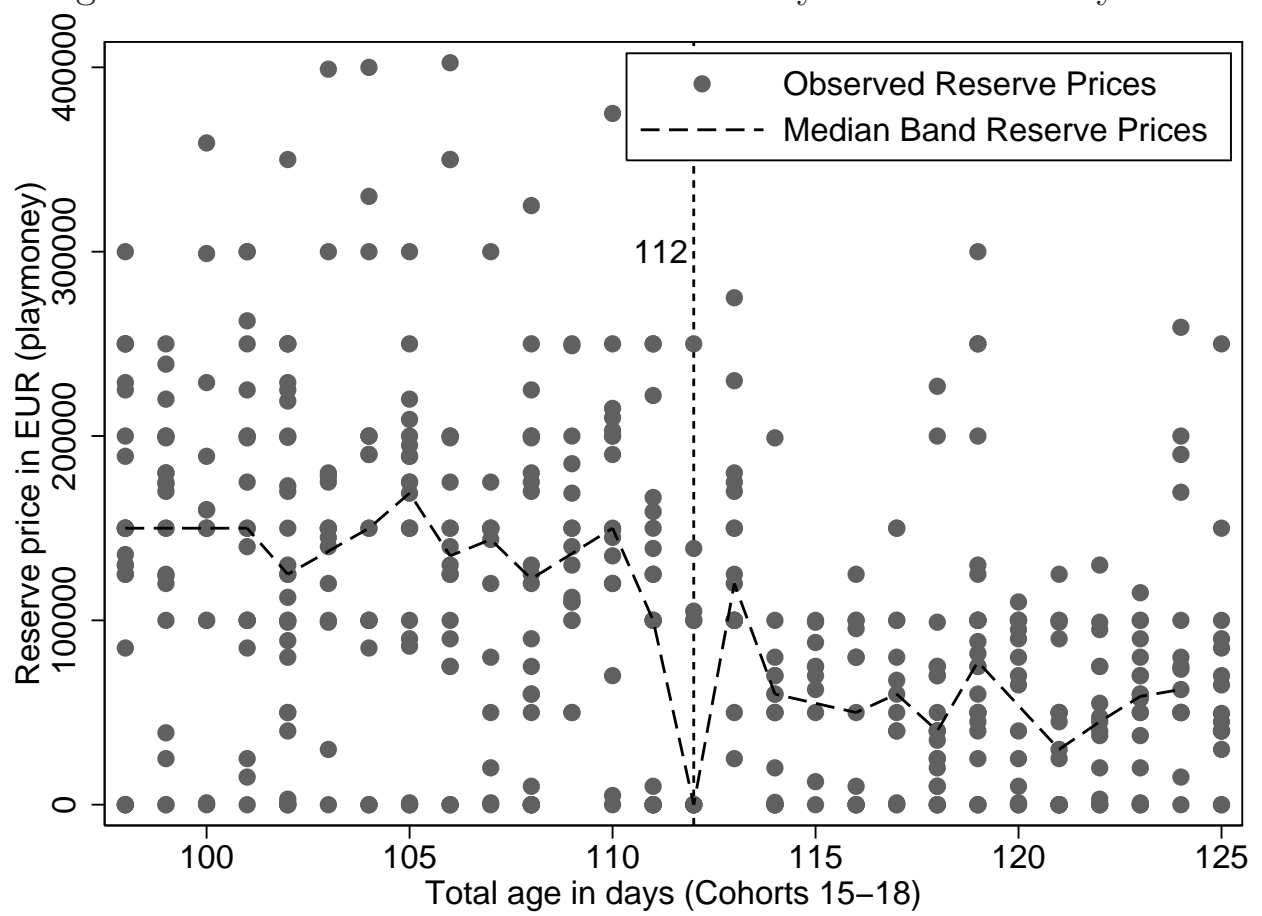

Notes: The figure depicts all reserve prices for players two weeks before and after their eighteens birthday at totalage $=112$, i.e. totalage $\in[98 ; 125]$ overall including 498 observations.

Figure 4: Patterns and Distribution of Reserve Prices
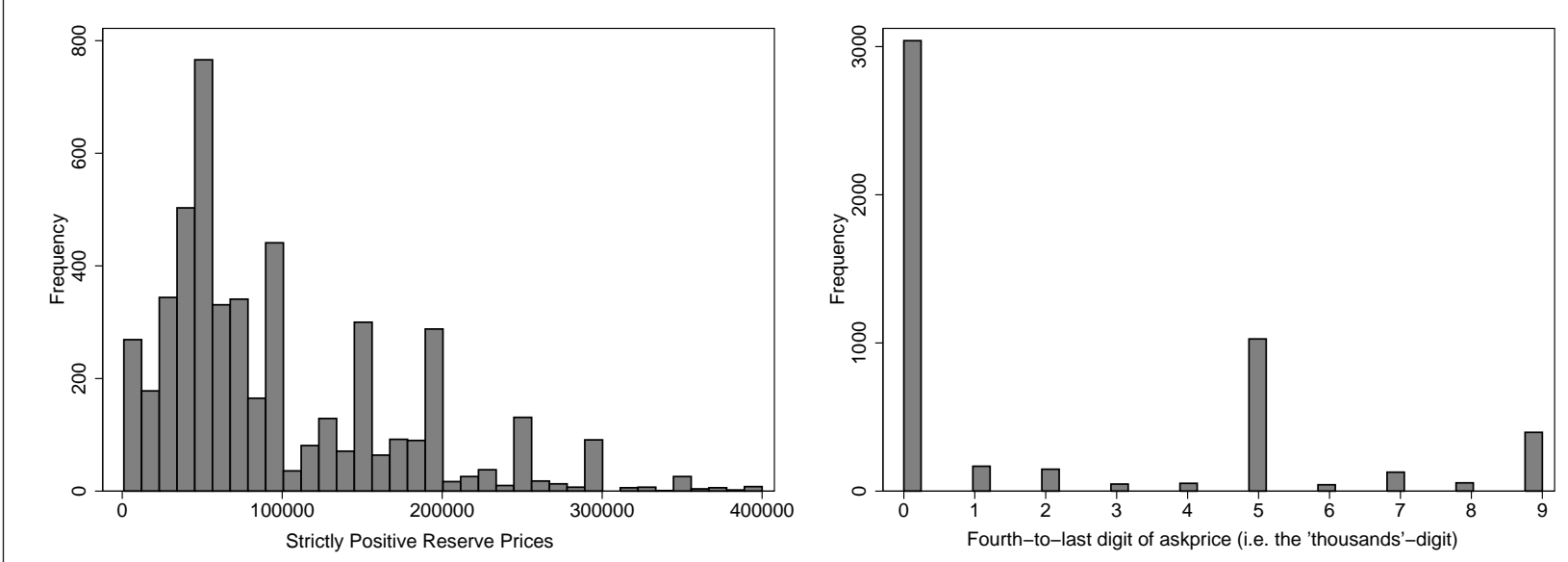

(a) Distribution non-zero reserve prices $^{a}$

(b) Frequency of forth-to-last digit of Reserve Prices ${ }^{b}$

a. The figure depicts the frequency of strictly positive reserve prices. The pattern clearly clusters around multiples of $€ 50000$. b. This histogram shows the frequency distribution of the fourth-to-last digit (the "thousands"-digit) of the (non-zero) reserve prices in the sample. For example, if askprice is $€ 67000$ the digit takes value "7". The spikes at the values of 0 , 5 and 9 indicate that a majority of reserve prices were set at multiples of $€ 5000$, or just below the next full ten-thousand. 
Figure 5: Screenshot of Player Profile with Auction Details

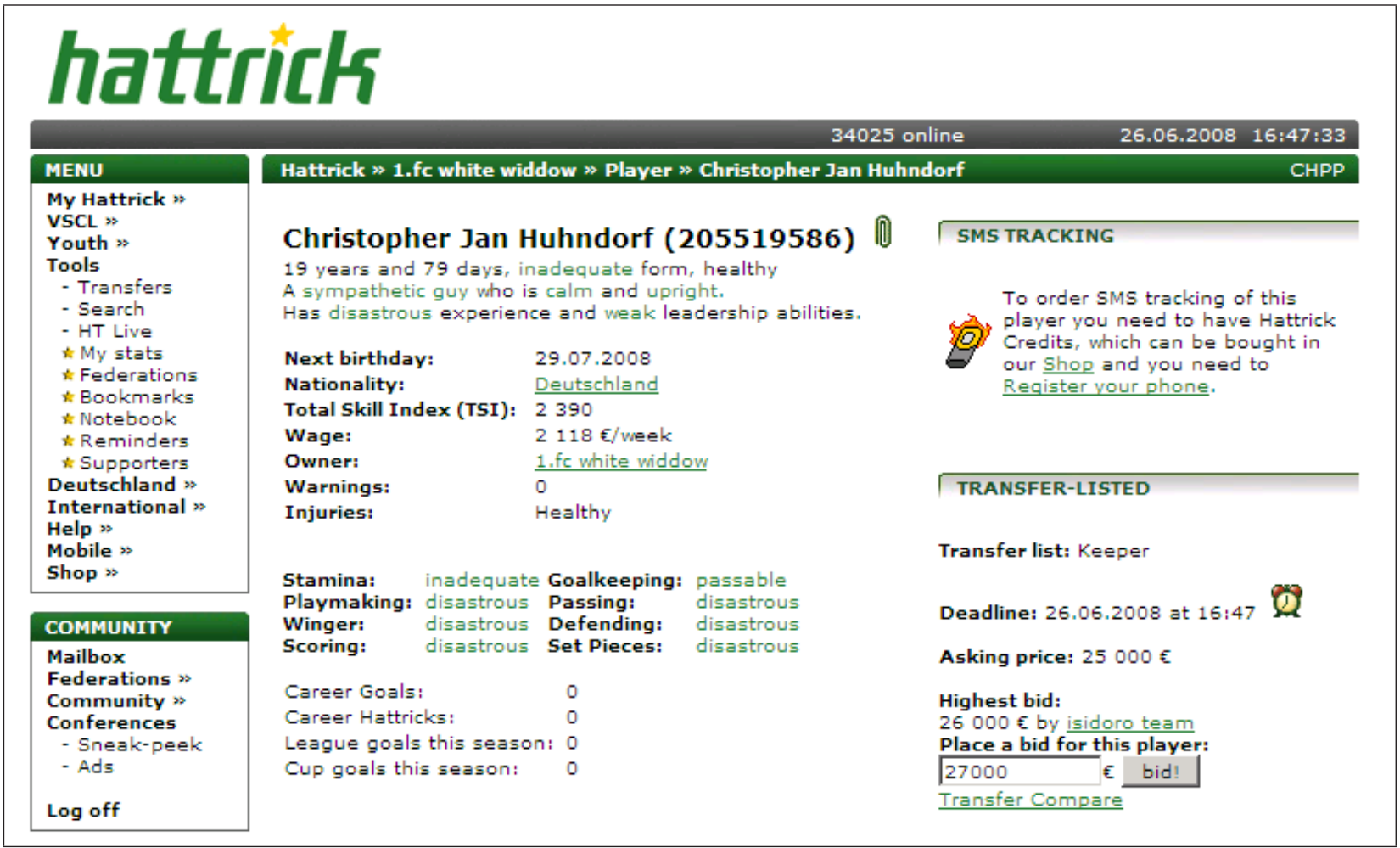

Notes: The figure shows the typical profile for a player on sale. Next to his full attribute vector, on the lower right all information regarding the auction details are displayed. The seller of this goalkeeper set him on the transfer market during the afternoon on June 23, 2008 (i.e. exactly 72 hours before the deadline displayed) at a reserve price of $€ 25000$. Unless no other manager submitted a higher amount before the deadline ended, the then-current highest bid of $€ 26000$ will have won the auction. (Source: www.hattrick.org) 


\section{CESifo Working Paper Series}

for full list see www.cesifo-group.org/wp

(address: Poschingerstr. 5, 81679 Munich, Germany, office@cesifo.de)

2309 Peter Egger and Doina Maria Radulescu, Labour Taxation and Foreign Direct Investment, May 2008

2310 Laurent Linnemer, Dissipative Advertising Signals Quality even without Repeat Purchases, May 2008

2311 Jordi Jofre-Monseny and Albert Solé-Ollé, Which Communities should be afraid of Mobility? The Effects of Agglomeration Economies on the Sensitivity of Firm Location to Local Taxes, May 2008

2312 Andreas Haufler and Ferdinand Mittermaier, Unionisation Triggers Tax Incentives to Attract Foreign Direct Investment, May 2008

2313 Ronel Elul and Piero Gottardi, Bankruptcy: Is it enough to Forgive or must we also Forget?, May 2008

2314 Andreas Irmen and Johanna Kuehnel, Productive Government Expenditure and Economic Growth, May 2008

2315 Beate Henschel, Carsten Pohl and Marcel Thum, Demographic Change and Regional Labour Markets: The Case of Eastern Germany, May 2008

2316 Gabriel Felbermayr, Wido Geis and Wilhelm Kohler, Restrictive Immigration Policy in Germany: Pains and Gains Foregone?, May 2008

2317 Michael Hofmann, Gerhard Kempkes and Helmut Seitz, Demographic Change and Public Sector Budgets in a Federal System, May 2008

2318 Paul De Grauwe, Macroeconomic Modeling when Agents are Imperfectly Informed, June 2008

2319 Johann K. Brunner and Susanne Pech, Optimum Taxation of Inheritances, June 2008

2320 Thomas Eichner and Marco Runkel, Corporate Income Taxation of Multinationals in a General Equilibrium Model, June 2008

2321 Rainald Borck and Matthias Wrede, Subsidies for Intracity and Intercity Commuting, June 2008

2322 Patricia Apps and Ray Rees, Testing the Pareto Efficiency of Household Resource Allocations, June 2008

2323 Amihai Glazer, Vesa Kanniainen and Panu Poutvaara, Firms' Ethics, Consumer Boycotts, and Signalling, June 2008 
2324 Claudia M. Buch, Jörg Döpke and Kerstin Stahn, Great Moderation at the Firm Level? Unconditional vs. Conditional Output Volatility, June 2008

2325 Helmuth Cremer, Philippe De Donder, Dario Maldonado and Pierre Pestieau, Forced Saving, Redistribution and Nonlinear Social Security Schemes, June 2008

2326 M. Hashem Pesaran and Paolo Zaffaroni, Optimal Asset Allocation with Factor Models for Large Portfolios, June 2008

2327 Harald Badinger and Peter Egger, Horizontal versus Vertical Interdependence in Multinational Activity, June 2008

2328 Jan K. Brueckner and Harris Selod, A Theory of Urban Squatting and Land-Tenure Formalization in Developing Countries, June 2008

2329 Paolo M. Panteghini, Corporate Debt, Hybrid Securities and the Effective Tax Rate, June 2008

2330 Guglielmo Maria Caporale, Juncal Cuñado and Luis A. Gil-Alana, Modelling Long-Run Trends and Cycles in Financial Time Series Data, June 2008

2331 Avi Ben-Bassat and Momi Dahan, Social Identity and Voter Turnout, June 2008

2332 Martin R. West and Ludger Wößmann, "Every Catholic Child in a Catholic School”: Historical Resistance to State Schooling, Contemporary Private Competition, and Student Achievement across Countries, June 2008

2333 Erkki Koskela and Panu Poutvaara, Outsourcing and Labor Taxation in Dual Labor Markets, June 2008

2334 Philippe Choné and Laurent Linnemer, Optimal Litigation Strategies with Signaling and Screening, June 2008

2335 Albert Solé-Ollé and Pilar Sorribas-Navarro, Does Partisan Alignment Affect the Electoral Reward of Intergovernmental Transfers?, June 2008

2336 Antonio Cabrales and Piero Gottardi, Markets for Information: Of Inefficient Firewalls and Efficient Monopolies, June 2008

2337 Sumon Majumdar and Sharun W. Mukand, The Leader as Catalyst - on Leadership and the Mechanics of Institutional Change, June 2008

2338 Ulrich Hange, Tax Competition, Elastic Labor Supply, and Growth, June 2008

2339 Guy Laroque and Bernard Salanié, Does Fertility Respond to Financial Incentives?, June 2008

2340 Adriano Paggiaro, Enrico Rettore and Ugo Trivellato, The Effect of Extending the Duration of Eligibility in an Italian Labour Market Programme for Dismissed Workers, June 2008 
2341 Helmut Seitz, Minimum Standards, Fixed Costs and Taxing Autonomy of Subnational Governments, June 2008

2342 Robert S. Chirinko, Leo de Haan and Elmer Sterken, Asset Price Shocks, Real Expenditures, and Financial Structure: A Multi-Country Analysis, July 2008

2343 Wolfgang Leininger, Evolutionarily Stable Preferences in Contests, July 2008

2344 Hartmut Egger and Udo Kreickemeier, Fairness, Trade, and Inequality, July 2008

2345 Ngo Van Long and Bodhisattva Sengupta, Yardstick Competition, Corruption, and Electoral Incentives, July 2008

2346 Florian Baumann, Employment Protection: The Case of Limited Enforceability, July 2008

2347 Alessandro Balestrino, Cinzia Ciardi and Claudio Mammini, On the Causes and Consequences of Divorce, July 2008

2348 Dirk Schindler and Benjamin Weigert, Insuring Educational Risk: Opportunities versus Income, July 2008

2349 Lammertjan Dam and Ben J. Heijdra, The Environmental and Macroeconomic Effects of Socially Responsible Investment, July 2008

2350 Avner Greif, Contract Enforcement and Institutions among the Maghribi Traders: Refuting Edwards and Ogilvie, July 2008

2351 Helmuth Cremer, Philippe De Donder, Dario Maldonado and Pierre Pestieau, Habit Formation and Labor Supply, July 2008

2352 Francesco Menoncin and Paolo M. Panteghini, The Johansson-Samuelson Theorem in General Equilibrium: A Rebuttal, July 2008

2353 Michael Kaganovich and Itzhak Zilcha, Alternative Social Security Systems and Growth, July 2008

2354 Keith Blackburn, Kyriakos C. Neanidis and M. Emranul Haque, Corruption, Seigniorage and Growth: Theory and Evidence, July 2008

2355 Edward Castronova, A Test of the Law of Demand in a Virtual World: Exploring the Petri Dish Approach to Social Science, July 2008

2356 Harald Badinger and Peter Egger, GM Estimation of Higher-Order Spatial Autoregressive Processes in Cross-Section Models with Heteroskedastic Disturbances, July 2008

2357 Wolfgang Buchholz and Jan Schumacher, Discounting the Long-Distant Future: A Simple Explanation for the Weitzman-Gollier-Puzzle, July 2008 
2358 Luca Anderlini, Leonardo Felli and Alessandro Riboni, Statute Law or Case Law?, July 2008

2359 Guglielmo Maria Caporale, Davide Ciferri and Alessandro Girardi, Are the Baltic Countries Ready to Adopt the Euro? A Generalised Purchasing Power Parity Approach, July 2008

2360 Erkki Koskela and Ronnie Schöb, Outsourcing of Unionized Firms and the Impacts of Labour Market Policy Reforms, July 2008

2361 Francisco Alvarez-Cuadrado and Ngo Van Long, A Permanent Income Version of the Relative Income Hypothesis, July 2008

2362 Gabrielle Demange, Robert Fenge and Silke Uebelmesser, Financing Higher Education and Labor Mobility, July 2008

2363 Alessandra Casarico and Alessandro Sommacal, Labor Income Taxation, Human Capital and Growth: The Role of Child Care, August 2008

2364 Antonis Adam, Manthos D. Delis and Pantelis Kammas, Fiscal Decentralization and Public Sector Efficiency: Evidence from OECD Countries, August 2008

2365 Stefan Voigt, The (Economic) Effects of Lay Participation in Courts - A Cross-Country Analysis, August 2008

2366 Tobias König and Andreas Wagener, (Post-)Materialist Attitudes and the Mix of Capital and Labour Taxation, August 2008

2367 Ximing Wu, Andreas Savvides and Thanasis Stengos, The Global Joint Distribution of Income and Health, August 2008

2368 Alejandro Donado and Klaus Wälde, Trade Unions Go Global!, August 2008

2369 Hans Gersbach and Hans Haller, Exit and Power in General Equilibrium, August 2008

2370 Jan P.A.M. Jacobs and Jan-Egbert Sturm, The Information Content of KOF Indicators on Swiss Current Account Data Revisions, August 2008

2371 Oliver Hülsewig, Johannes Mayr and Timo Wollmershäuser, Forecasting Euro Area Real GDP: Optimal Pooling of Information, August 2008

2372 Tigran Poghosyan and Jakob de Haan, Determinants of Cross-Border Bank Acquisitions in Transition Economies: A Latent Class Analysis, August 2008

2373 David Anthoff and Richard S.J. Tol, On International Equity Weights and National Decision Making on Climate Change, August 2008

2374 Florian Englmaier and Arno Schmöller, Reserve Price Formation in Online Auctions, August 2008 